\title{
KELAYAKAN SISTEM SALURAN DRAINASE MENINJAU SUPPLY DAN DEMAND UNTUK MENDUKUNG RENCANA KAWASAN PERKOTAAN PRINGSEWU
}

\author{
Fatmawati Hajar Aswad ${ }^{1}$, Lutfi Setianingrum ${ }^{1}$ \\ ${ }^{1}$ Program Studi Perencanaan Wilayah dan Kota, Institut Teknologi Sumatera \\ ${ }^{1}$ Email : fatmawati.22117093@student.itera.ac.id
}

DOI : 10.35472/jppk.v1i2.500

\begin{abstract}
Pringsewu Regency is a district that is currently focusing on the preparation and maturation of the 2011 2031 Regional Spatial Plan, in which the RTRW has plans to prepare it to become an urban area. In order to have good city management, it is necessary to study the feasibility of the drainage system which can later be used as input for careful planning to support the Pringsewu Urban Area plan by taking into account the availability and quantity of drainage channels so as not to cause a disaster problem in the future. This study uses a deductive approach, namely in order to obtain conclusions regarding the feasibility of data in the form of facts in the field in general and be interpreted. Based on the results of the analysis that has been carried out, the ability of the drainage channel is Qtotal>Qchannel so that the channel cannot accommodate rainwater and wastewater. So that to support the Pringsewu Urban Area, the current drainage channel can be said to be less feasible when viewed in terms of infrastructure, namely the existing drainage system.
\end{abstract}

Keywords: Drainage, Urban Area.

\section{A. PENDAHULUAN}

Kabupaten Pringsewu saat ini sedang fokus terhadap penyusunan dan pematangan Rencana Tata Ruang Wilayah tahun 2011-2031 yang dalam RTRW tersebut adanya rencana mengenai persiapan menjadi kawasan perkotaan. Berdasarkan data hasil monitoring yang tertuang dalam dokumen evaluasi pemanfaatan ruang di Dinas Pekerjaan Umum dan Permukiman Rakyat Kabupaten Pringsewu tahun 2015-2020 saluran drainase dari memiliki tingkat kualitas yang lebih rendah dengan persentase 50\% yang berarti tidak berkualitas. Menurut Muslinah (2019) daerah aliran sungai di Kabupaten Pringsewu terletak dibagian hilir yang berasal dari wilayah tangkapan air Kabupaten Tanggamus yang mana daerah aliran sungai bagian hilir. Serta diperkuat berdasarkan informasi yang didapatkan dari lampost.co yakni, pada bulan Februari 2021 terjadi bencana banjir di sejumlah kecamatan akibat meluap serta terjadi banjir kiriman dari sungai Way Mincang yang berasal dari Kabupaten Pesawaran dengan ketinggian antara 10-30 cm dan menggenangi sebagian ruas jalan lintas barat dan permukiman dengan waktu genangan antara 2-3 jam.

Maka dari itu, guna mempersiapkan Rencana Kawasan Perkotaan Pringsewu dengan kualitas manajemen kota yang baik guna mencegah terjadinya permasalahan kebencanaan yang disebabkan oleh saluran drainase yang belum sesuai fungsinya pada rencana kawasan perkotaan diperlukannya tingkat kelayakan sistem saluran drainase untuk mendukung rencana Kawasan Perkotaan Pringsewu. 


\section{B. METODE PENELITAN}

\subsection{Metode Pendekatan dan Pengumpulan Data}

Pada penelitian ini untuk mengetahui kesesuaian standar kelayakan sistem jaringan drainase sebagai salah satu jaringan perkotaan yang nantinya dapat mendukung suatu kabupaten dalam menyiapkan menjadi kawasan perkotaan yakni menggunakan pendekatan deduktif dengan jenis penelitian Mix Method. Menurut Supriyati (2013) bahwa penelitian ini merupakan jenis penelitian mix methods yang merupakan metode gabungan antara penelitian kuantitatif dan kualitatif.

\subsection{Metode Pengumpulan}

Metode pengumpulan data berupa data sekunder yakni meninjau dari tinjauan pustaka serta data primer melalui wawancara terstruktur kepada stakeholder terkait, observasi atau survei lapangan dan dokumentasi mengenai data yang peneliti butuhkan sebagai pendukung data yang akurat.

\subsection{Metode Analisis}

Teknik analisis yang digunakan dalam penelitian ini adalah sebagai berikut:

1) Teknik Analisis Debit Limpasan Air Hujan.

Perhitungan debit limpasan dapat dihitung dengan rumus berikut:

$$
Q T=0,278 \times C X I X A
$$

Keterangan $=$

QT : debit limpasan permukaan (m3/dt) dengan periode ulang $\mathrm{T}$ tahun.

0,278 : faktor konversi satuan

$\mathrm{C}$ : koefisien pengaliran

I : intensitas hujan ( $\mathrm{mm} / \mathrm{jam})$ dengan periode ulang $\mathrm{T}$ tahun

A : luas daerah pengaliran (tata gua lahan) $(\mathrm{km} 2)$

a) Koefisien Pengaliran (C)

Menurut Paramitha \& Rauf (2018) koefesien limpasan ( C ) merupakan perbandingan curah limpasan dengan tebal hujan $(\mathrm{P})$ pada daerah tangkapan air yang dimana nilai koefisien $(\mathrm{C})$ dapat dihitung dengan rumus :

$$
C=(Q / P) / \text { Luas DTA }
$$

Keterangan :

$\mathrm{C}=$ Koefisien Pengaliran

$\mathrm{Q}=$ Debit Harian

$\mathrm{P}=$ Curah Hujan

Luas DTA = Daerah Tangkapan Air

Menurut Madhatillah, \& HAR, R. (2018), Pada DAS yang baik memiliki nilai mendekati 0 (nol) dan semakin rusak DAS memiliki nilai $\mathrm{C}$ mendekati 1. 
b. Intensitas Curah Hujan

Menurut Madhatillah, \& HAR, R. (2018), untuk mengolah data curah hujan menjadi intensitas curah hujan salah satunya dapat memakai metode mononobe dengan menggunakan rumus :

$$
I=(X t / 244)(24 / T c)^{2 / 3}
$$

Keterangan :

I : Intensitas curah hujan (mm/jam)

$\mathrm{Xt}$ : hujan harian maksimum/ Curah hujan rencana (mm/hari) Tc : waktu tiba banjir/waktu konsetrasi (jam)

2) Perhitungan Air Buangan

Guna mengetahui kebutuhan air bersih dapat menggunakan rumus:

$$
\text { Kebutuhan air bersih }=\frac{\text { Jumlah Penduduk }\left(\frac{\text { Jiwa }}{\text { tahun }}\right)}{\text { Standar Air Bersih }(\text { Kawasan })}
$$

Menentukan kebutuhan air domestik dapat menggunakan rumus :

$$
Q=P n X q
$$

Keterangan :

$\mathrm{Q} \quad=$ Kebutuhan Air Bersih

Pn = Jumlah Penduduk tahun $\mathrm{n}$

Q = Kebutuhan Air per orang/hari

Kebutuhan air harian maksimum (Qrhm) yakni banyaknya air yang dibutuhkan pada satu hari:

$$
\text { Qrhm }=\text { Fhm } X \text { Qrh }
$$

Keterangan:

Qrhm : Kebutuhan air harian maksimum

Fhm: Faktor kebutuhan harian maksimum (1.05-1.15)

Qrhm : Kebutuhan air harian rata-rata

kemudian dapat dihitung air limbah yang $60 \%$ berasal dari ketersediaan air bersih dengan rumus :

Air Limbah = 0,6 x Q Air Bersih x Jumlah Penduduk

\section{HASIL DAN PEMBAHASAN}

\subsection{Analisis Demand Saluran Drainase Di Kawasan Perkotaan Pringsewu}


Analisis demand saluran drainase dapat berupa perhitungan debit limpasan serta volume air limbah yang nantinya dapat diketahui daya tampung saluran drainase di Kawasan Perkotaan Pringsewu yang dapat dilihat pada tabel berikut

Tabel 1. Debit Volume Air Limbah Kawasan Perkotaan Pringsewu

\begin{tabular}{|c|c|}
\hline KECAMATAN & $\begin{array}{c}\text { Volume Air } \\
\text { Limbah }(\mathrm{m} 3 / \mathrm{s})\end{array}$ \\
\hline Ambarawa & 0.0017 \\
\hline Pagelaran & 0.0027 \\
\hline Pringsewu & 0.0045 \\
\hline Gading Rejo & 0.004 \\
\hline Sukoharjo & 0.0028 \\
\hline
\end{tabular}

Dari tabel di atas, maka dapat dikatakan bahwasannya, air limbah yang dihasilkan telah melewati dari batas rata-rata volume air limbah atau Qlimbah < Qr yang dihasilkan dimasing-masing kecamatan di Kawasan Perkotaan Pringsewu.

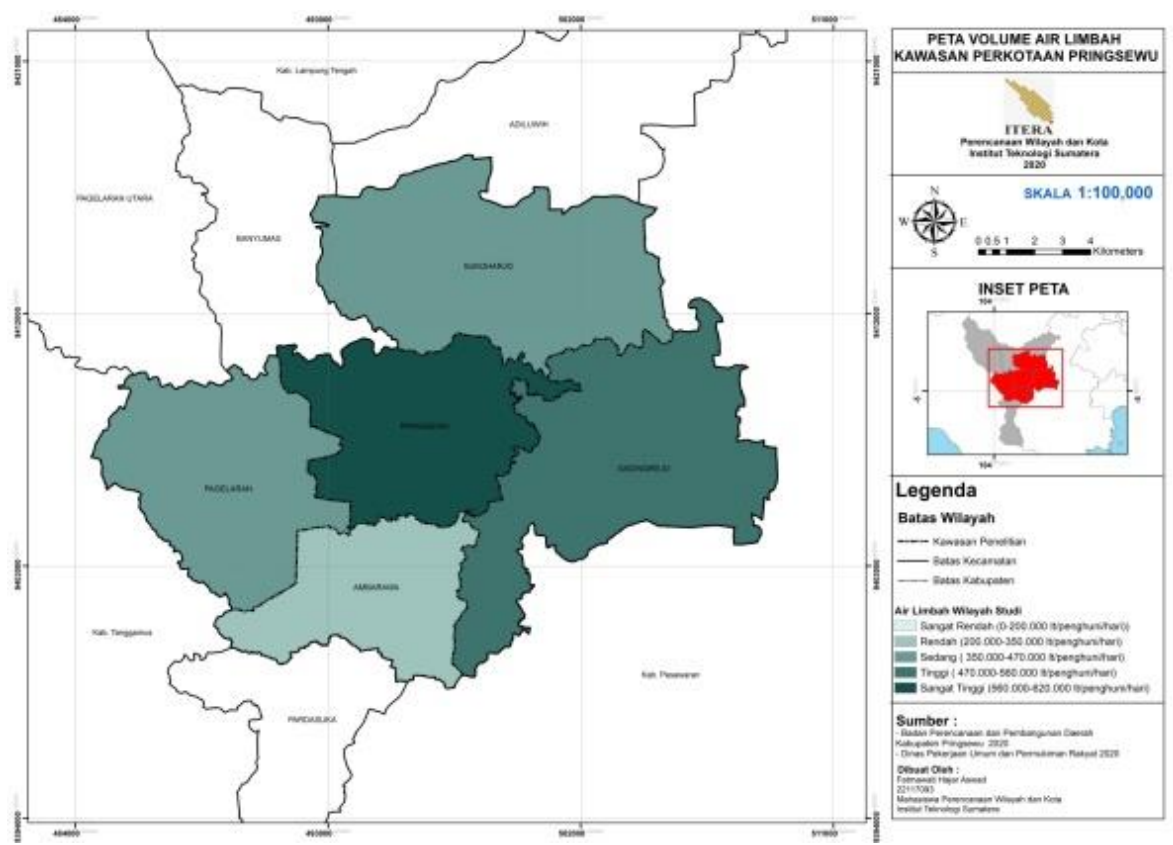

Sumber : Hasil Olah Data Penelitian,2021

Gambar 1. Peta Volume Air Limbah Kawasan Perkotaan Pringsewu

Dari peta di atas pada gambar 4 halaman 10 dapat diketahui, bahwasannya air limbah domestik terbanyak dihasilkan oleh Kecamatan Pringsewu dengan air limbah domestik sebesar 628815 liter/penghuni/hari dengan jumlah penduduk yakni 76.220 jiwa. a. Analisis Curah Hujan Di Kawasan Perkotaan Pringsewu

Berikut merupakan curah hujan rata-rata yang dapat dilihat pada tabel sebagai berikut. 
Tabel 2. Curah Hujan Tahunan Berdasarkan Bulan Di Kawasan Perkotaan Pringsewu

\begin{tabular}{|c|c|c|c|c|c|}
\hline Tahun & Pringsewu & $\begin{array}{c}\text { Gading } \\
\text { Rejo }\end{array}$ & Sukoharjo & Pagelaran & Ambarawa \\
\hline 2015 & 154.17 & 119.5 & 94 & 133.7 & 116.79 \\
\hline 2016 & 225.75 & 147.3 & 154.3 & 179.8 & 177.88 \\
\hline 2017 & 147.83 & 142.8 & 142.9 & 140.8 & 132.43 \\
\hline 2018 & 125.67 & 102.4 & 109.5 & 142.5 & 136.66 \\
\hline 2019 & 128.67 & 111.3 & 121.3 & 124.2 & 121.25 \\
\hline 2020 & 205.08 & 146.2 & 172.1 & 171.9 & 128.23 \\
\hline
\end{tabular}

Sumber: BMKG Kabupaten Pesawaran,2020

Menurut Susilowati \& Sadad (2015) bahwasannya intensitas curah hujan merupakan ketinggian hujan yang terjadi dalam kurun waktu pendek yang dapat memberikan gambaran derasnya hujan perjamnya. Berdasarkan tabel di atas bahwasannya nilai minimum curah hujan rencana pada Kecamatan Sukoharjo terdapat pada tahun $94,00 \mathrm{~mm}$ dan nilai maksimum curah hujan rencana terdapat pada tahun 2020 sebesar $172,08 \mathrm{~mm}$.

b. Debit Limpasan Drainase Rencana Kawasan Perkotaan Pringsewu

Debit limpasan dihitung menggunakan metode rasional dan intensitas menggunakan metode manobe yang dapat dihitung debit limpasan Di Kawasan Perkotaan Pringsewu sebagai berikut :

Tabel 3. Debit Limpasan Dengan Uji Gumbel Di Kawasan Perkotaan Pringsewu

\begin{tabular}{|c|c|c|c|c|c|}
\hline Kecamatan & $\begin{array}{c}\text { Periode } \\
\text { Ulang } \\
\text { (tahun) }\end{array}$ & $\mathbf{C}$ & I (mm/jam) & $\begin{array}{c}A \\
\left(\mathrm{~km}^{2}\right)\end{array}$ & $\mathbf{Q}\left(\mathbf{m}^{3} / \mathbf{s}\right)$ \\
\hline Pringsewu & \multirow{5}{*}{2} & 0.51 & 20.44 & 40.18 & 1.2 \\
\hline Gading Rejo & & 0.51 & 14.71 & 49.82 & 1.09 \\
\hline Sukoharjo & & 0.45 & 15.23 & 47.54 & 0.94 \\
\hline Pagelaran & & 0.48 & 18.6 & 39.06 & 1 \\
\hline Ambarawa & & 0.52 & 18.11 & 26.54 & 0.72 \\
\hline
\end{tabular}

Sumber : Hasil Olah Data Penelitian,2021

Setelah didapatkan debit limpasan kemudian dapat dianalisis dan dijadikan dalam bentuk peta debit limpasan rencana Kawasan Perkotaan Pringsewu sebagai berikut 


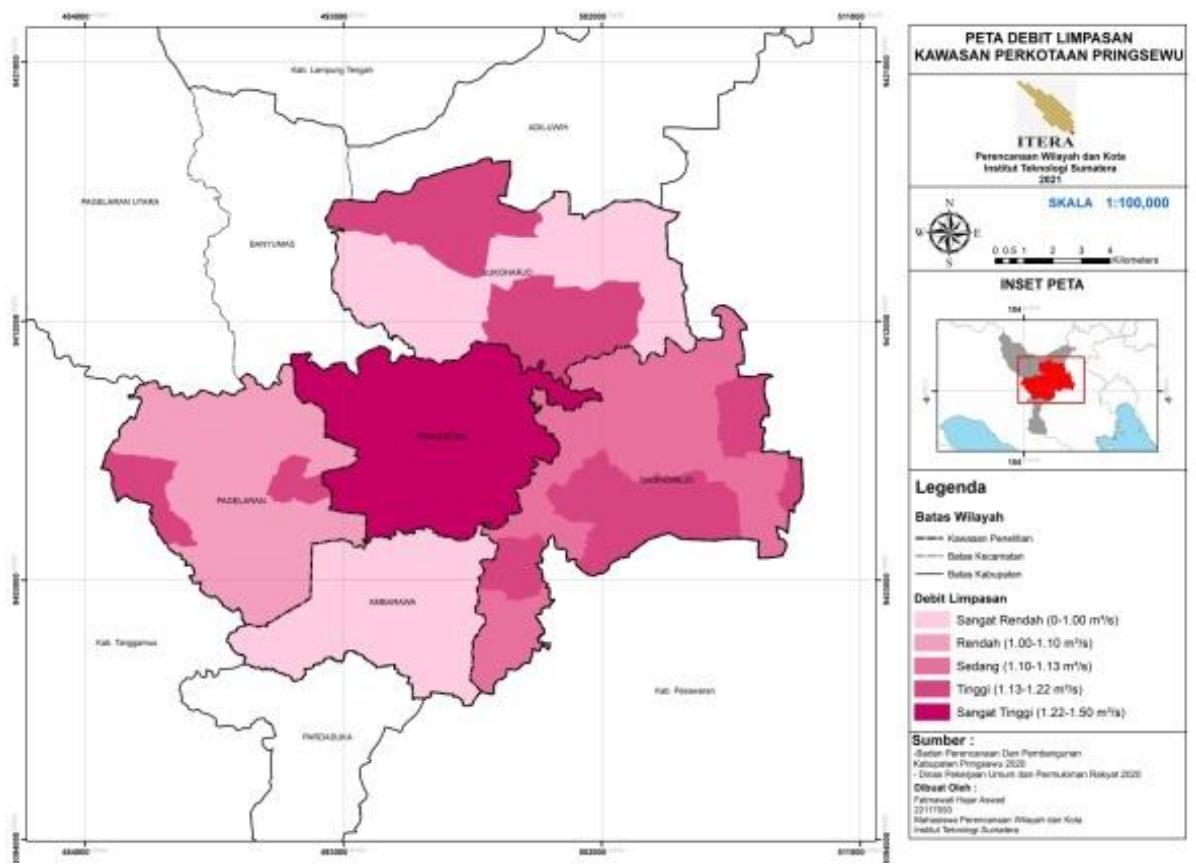

Sumber : Hasil Olah Data Penelitian,2021

Gambar 2. Peta Debit Limpasan Kawasan Perkotaan Pringsewu

Dari analisis yang telah didapatkan bahwasannya debit limpasan sangat tinggi yakni sebesar $1.26 \mathrm{~m}^{3} / \mathrm{s}$ yang terdapat pada Kecamatan Pringsewu , tinggi didominasi pada sebagian Kecamatan Gading Rejo yakni sebesar $1.10 \mathrm{~m}^{3} / \mathrm{s}$ dan debit limpasan sangat rendah berada pada Kecamatan Ambarawa dengan nilai sebesar $0.72 \mathrm{~m} 3 / \mathrm{s}$ dan sebagian Kecamatan Sukoharjo yakni sebesar $0.96 \mathrm{~m}^{3} / \mathrm{s}$

\subsection{Analisis Supply Saluran Drainase Di Kawasan Perkotaan Pringsewu}

Berikut merupakan tabel hasil perhitungan Qsaluran serta kondisi kapasitas saluran pada kuru waktu 2 tahun pada masing-masing kecamatan pada rencana kawasan perkotaan.

Tabel 4. Hasil Perhitungan Debit Saluran Serta Kapasitas Saluran Pada Kawasan Perkotaan Pringsewu

\begin{tabular}{|c|c|c|}
\hline Wilayah Observasi & $\begin{array}{c}\text { Q saluran } \\
\left(\mathbf{m}^{3} / \mathbf{s}\right)\end{array}$ & QLimpasan $\left(\mathbf{m}^{3} / \mathbf{s}\right)$ \\
\hline Kecamatan Ambarawa & \multirow{5}{*}{0.37} & 0.72 \\
\hline Kecamatan Gading Rejo & & 1.1 \\
\hline Kecamatan Pagelaran & & 1 \\
\hline Kecamatan Pringsewu & & 1.26 \\
\hline Kecamatan Sukoharjo & & 0.96 \\
\hline
\end{tabular}

Maka dari hasil analisis yang telah didapatkan bahwasannya pada rencana kawasan perkotaan Pringsewu pada periode ulang 2 tahun memiliki Q limpasan $>$ Q saluran drainase yang mana pada Kecamatan Pringsewu memiliki Q limpasan $\left(1.22 \mathrm{~m}^{3} / \mathrm{s}\right)>\mathrm{Q}$ 
saluran $\left(0.38 \mathrm{~m}^{3} \mathrm{~s}\right)$, Kecamatan Gading Rejo memiliki Q limpasan $\left(1.10 \mathrm{~m}^{3} / \mathrm{s}\right)>\mathrm{Q}$ saluran $\left(0.38 \mathrm{~m}^{3} / \mathrm{s}\right)$, Kecamatan Sukoharjo memiliki Q limpasan $(0.96 \mathrm{~m} / \mathrm{s})>\mathrm{Q}$ saluran $\left(0.38 \mathrm{~m}^{3} / \mathrm{s}\right)$, Kecamata Pagelaran memiliki Q limpasan $\left(1.00 \mathrm{~m}^{3} / \mathrm{s}\right)>$ Q saluran $\left(0.38 \mathrm{~m}^{3} / \mathrm{s}\right)$ dan Kecamatan Ambarawa memiliki Q limpasan $\left(0.72 \mathrm{~m}^{3} / \mathrm{s}\right)>\mathrm{Q}$ saluran $\left(0.38 \mathrm{~m}^{3} / \mathrm{s}\right)$. Hal ini diperkuat Yelsa,dkk (2012) bahwasannya apabila Q limpasan > Q saluran maka diperlukannya normalisasi untuk memperbesar kapasitas saluran agar dapat mengaliri air hujan dan air buangan sehigga tidak menyebabkan permasalahan pada saluran drainase apabila nantinya Kawasan Perkotaan Pringsewu ini terwujud.

\subsection{Analisis Supply dan Demand Saluran Drainase Di Kawasan Perkotaan Pringsewu}

Berikut merupakan tabel hasil perhitungan Qtotal serta kapasitas saluran drainase pada rencana Kawasan Perkotaan Pringsewu yang dapat dilihat sebagai berikut.

Tabel 5. Perhitungan Kapasaitas Saluran Drainase Di Kawasan Perkotaan Pringsewu

\begin{tabular}{|l|c|c|c|c|}
\hline Wilayah Observasi & $\begin{array}{c}\text { Q debit } \\
\text { Limpasan } \\
\left(\mathbf{m}^{\mathbf{3}} / \mathbf{s}\right)\end{array}$ & $\begin{array}{c}\text { Qlimbah } \\
\mathbf{( \mathbf { m } ^ { 3 } / \mathbf { s } )}\end{array}$ & $\begin{array}{c}\text { Qtotal } \\
\mathbf{( \mathbf { m } ^ { 3 } / \mathbf { s } )}\end{array}$ & $\begin{array}{c}\text { Kesesuaian } \\
\text { Kapasitas } \\
\text { Saluran }\left(\mathbf{m}^{3} \mathbf{s}\right)\end{array}$ \\
\hline $\begin{array}{l}\text { Kecamatan } \\
\text { Ambarawa }\end{array}$ & 0.72 & 0,0017 & 0,73 & -0.36 \\
\hline $\begin{array}{l}\text { Kecamatan Gading } \\
\text { Rejo }\end{array}$ & 1.1 & 0,040 & 1,13 & -0.76 \\
\hline $\begin{array}{l}\text { Kecamatan } \\
\text { Pagelaran }\end{array}$ & 1 & 0,0027 & 1,01 & -0.64 \\
\hline $\begin{array}{l}\text { Kecamatan } \\
\text { Pringsewu }\end{array}$ & 1.26 & 0,0045 & 1,23 & -0.86 \\
\hline $\begin{array}{l}\text { Kecamatan } \\
\text { Sukoharjo }\end{array}$ & 0.96 & 0,0028 & 0,95 & -0.58 \\
\hline
\end{tabular}

Sumber : Hasil Olah Data Peneliti,2021

Dapat diketahui bahwasannya pada Kecamatan Ambarawa memiliki Qtotal>Qsaluran yakni $0,73 \mathrm{~m}^{3} / \mathrm{s}>0.38 \mathrm{~m}^{3} / \mathrm{s}$ dengan kapsitas saluran kurang $-0,36 \mathrm{~m}^{3} / \mathrm{s}$. Kemudian, Kecamatan Gading Rejo Qtotal>Qsaluran yakni $1,13 \mathrm{~m}^{3} / \mathrm{s}>0.38 \mathrm{~m}^{3} / \mathrm{s}$ dengan kapsitas saluran kurang $-0,76 \mathrm{~m}^{3} / \mathrm{s}$. Kecamatan Pagelaran memiliki Q total $>$ Qsaluran yakni $1,01 \mathrm{~m}^{3} / \mathrm{s}>0.38 \mathrm{~m}^{3} / \mathrm{s}$ dengan kapsitas saluran kurang $-0,64 \mathrm{~m}^{3} / \mathrm{s}$. Kecamatan Pringsewu memiliki Q total $>$ Qsaluran yakni $1,23 \mathrm{~m}^{3} / \mathrm{s}>0.38 \mathrm{~m}^{3} / \mathrm{s}$ dengan kapsitas saluran kurang $-0,86 \mathrm{~m}^{3} / \mathrm{s}$. dan Kecamatan Sukoharjo memiliki yakni Qtotal>Qsaluran yakni 0,95 $\mathrm{m}^{3} / \mathrm{s}>0.38 \mathrm{~m}^{3} / \mathrm{s}$ dengan kapsitas saluran kurang $-0,58 \mathrm{~m}^{3} / \mathrm{s}$. Kemudian guna dapat memperjelas penjelasan dari tabel diatas, maka dapat disajikan dalam bentuk peta dibawah ini. 

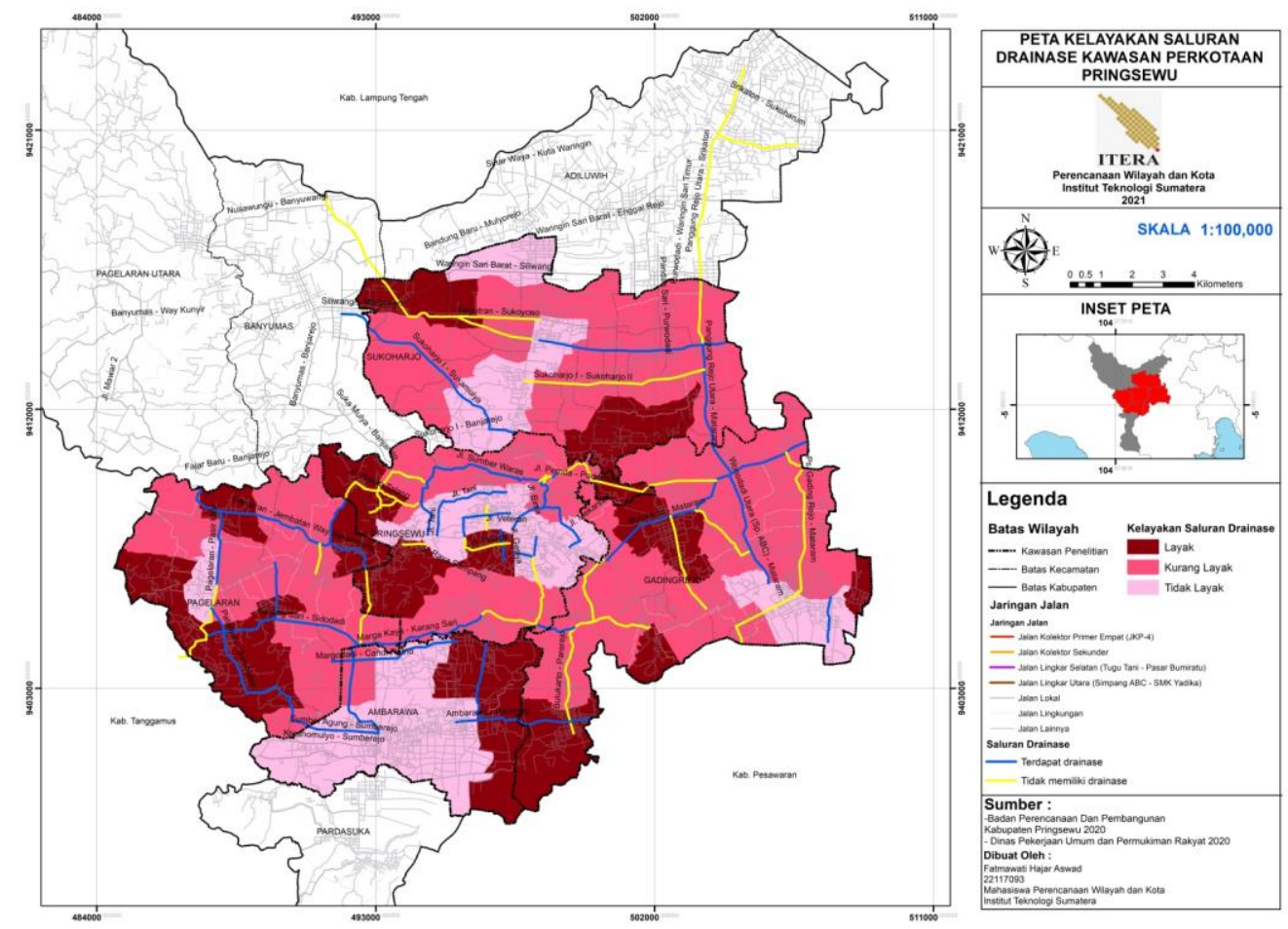

Sumber : Hasil Olah Data Penelitian,2021

Gambar 3. Peta Kelayakan Saluran Drainase Kawasan Perkotaan Pringsewu

Berdasarkan peta bahwasannya daerah dengan debit limpasan air hujan serta air limbah yang dihasilkan yakni kurang layak. Apabila meninjau klasifikasi kelayakan bahwasnnya daerah yang dikategorikan tidak layak yakni belum tersedianya saluran drainase serta beberapa memiliki waktu genangan atau banjir sekitar kurang lebih 11,5 jam bahwasannya menurut Menurut Saktyanu (2016) daerah yang memiliki waktu hujan $>8$ jam dikategorikan daerah yang sangat tinggi untuk terjadinya banjir ataupun genangan. Sehingga daerah tersebut merupakan daerah prioritas dan perlu dilakukannya normalisasi serta perbaikan pada saluran drainase agar dapat mendukung rencana Kawasan Perkotaan Pringsewu yang nantinya dapat menampung air hujan dengan intensitas yang tinggi disertai air limbah yang menyebabkan terjadi pelimpahan air hujan ke jalan raya pada daerah Kawasan Perkotaan Pringsewu.

\subsection{KESIMPULAN}

Berdasarkan hasil analisis yang telah didapatkan bahwasannya kemampuan daya tampung saluran drainase pada rencana Kawasan Perkotaan Pringsewu yakni memiliki Qtotal>Qsaluran dengan ketersediaan saluran drainase hanya 66\% dibawah standar kelayakan saluran drainase yang seharusnya tersedia $88 \%$ saluran drainase yang tersebar pada kawasan perkotaan. Sehingga kelayakan saluran drainase dapat dikatakan cukup rendah dengan ketersediaan drainase yang ada untuk mendukung adanya rencana Kawasan Perkotaan Pringsewu yang menyebabkan saluran drainase belum dapat menampung dan memenuhi kebutuhan kawasan perkotaan dalam mengaliri atau mengeringkan air permukaan. Sehingga, masih terdapatnya beberapa daerah tergenang 
akibat luapan sungai disertai air hujan serta limbang yang tidak mampu ditampung oleh drainase.

Maka dari itu, apabila ingin mendukung adanya rencana Kawasan Perkotaan Pringsewu yang memperhatikan prasarana dari segi sistem saluran drainase diperlukannya penambahan ataupun peningkatan kualitas saluran drainase agar saluran drainase dapat menunjang dalam hal menanggulangi permasalahan banjir atau kelebihan air dalam air pembuangan di Kawasan Perkotaan Pringsewu.

\section{DAFTAR PUSTAKA}

[1] Badan Meteorologi Klimatologi dan Geofisika Kabupaten Pesawaran Tahun 2020. (n.d.). Data Curah Hujan Kabupaten Pringsewu Tahun 2020.

[2] Madhatillah, \& HAR, R. (2018). Analisis Debit Air Limpasan Permukaan (Run Off) Akibat PErubahan Tata Guna Lahan Pada DAS Kuranji dan DAS Batang Arau Kota Padang. Jurnal Bina Tambang, 179-180.

[3] Paramitha, T. A., \& Rauf, A. (2018). Nilai Koefisien Limpasan (C) Sub DAS Taripa Di Kecamatan Toaya Kabupaten Donggala Provinsi Sulawesi Tengah. Jurnal Warta Rimba, 105-106.

[4] Peraturan Daerah Kabupaten Pringsewu Nomor 02 Tahun 2012 tentang Rencana Tata Ruang Wilayah Kabupaten Pringsewu tahun 2012-2031

[5] Peraturan Menteri Agraria dan Tata Ruang/Kepala Badan Pertahanan Nasional Republik Indonesia Nomor 09 Tahun 2017 Tentang Pedoman Pemantauan dan Evaluasi Pemanfaatan Ruang.

[6] Pratiwi, R. S., \& Purwati, I. F. (2015). Perencanaan Sistem Penyaluran Air Limbah Domestik Di Kelurahan Keputih Surabaya. Teknik ITS Vol.4 No.1 , 41-42.

[7] Rahmani, R. N., Sobriyah, \& Wahyudi, A. H. (2016). Transformasi Hujan Harian Ke Hujan Jam-Jaman Menggunakan Metode Manobe dan Pengalirangaman Hujan Aliran. Matriks Teknik Sipil, 177-178.

[8] Saktyanu P,M.Eng.Sc, I. (2016). Modul Prinsip-Prinsip dan Permasalahan Penanganan Drainase Jalan yang Berkelanjutan. Yogyakarta: Sistem Manajemen Pengetahuan.

[9] Supriyati, N. (2013). Metode Penelitian Gabungan (Mixed Methods). Surabaya: Widyaiswara BDK Surabaya.

[10] Susilowati, \& Sadad, I. (2015). Analisis Karakteristik Curah Hujan Di Kota Bandar Lampung. Konstruksia Vol.7 No.1, 15.

[11] Yelsa, M., Nugroho, J., \& Natasaputra, S. (2012). Pengaruh Perubahan Tata Guna Lahan terhadap Debit Limpasan Drainase Di Kota Bukittinggi. 11.

[12] https://www.mongabay.co.id/2019/08/17/di-sungai-kering-warga-way-bulokgelar-upacara-kemerdekaan-indonesia/,Eni Muslinah (2019,Agustus 17). Diakses Tanggal : 18 April 2021/Pukul:14.43 WIB 